\title{
Neutrophil to lymphocyte ratio is a better indicator of COPD exacerbation severity in neutrophilic endotypes than eosinophilic endotypes
}

This article was published in the following Dove Press journal: International Journal of COPD

\author{
Emine Aksoy \\ Zuhal Karakurt \\ Sinem Gungor \\ Birsen Ocakli \\ İpek Ozmen \\ Elif Yildirim \\ Eylem Tuncay \\ Meltem Coban Agca \\ Nezihe Ciftaslan \\ Goksenoglu \\ Nalan Adigüzel
}

Respiratory Intensive Care Unit Clinic, Sureyyapasa Chest Diseases and Thoracic Surgery Teaching and Research Hospital, Istanbul, Turkey
Correspondence: Zuhal Karakurt Health Sciences University, Sureyyapașa Chest Diseases and Thoracic Surgery Training and Research Hospital, Respiratory Intensive Care Unit, Soyak Yenișehir Manolya Evleri B3/Daire 63 Umraniye/İstanbul, Turkey

Tel +90 5326466590

Email zuhalkarakurt@hotmail.com
Background: Complete blood count parameters provide novel inflammatory markers, namely neutrophil to lymphocyte ratio (NLR) and platelet to lymphocyte ratio (PLR). We aimed to assess any differences in these novel inflammatory markers according to exacerbation severity in patients with COPD in both eosinophilic and neutrophilic endotypes.

Method: This retrospective cross-sectional study was conducted at a tertiary education hospital. Previously diagnosed COPD patients admitted to the hospital with acute COPD exacerbation (AECOPD) were enrolled into the study. Patients were grouped according to COPD endotype, eosinophilic (peripheral blood eosinophil rate $\geq 2 \%$ ) and neutrophilic (peripheral blood eosinophil rate $<2 \%$ ), and further subdivided according to place of admission (outpatient clinic, ward, or intensive care unit [ICU]) as an indicator of disease severity. Complete blood count, biochemistry, C-reactive protein (CRP), NLR, PLR, and platelet to mean platelet volume values were recorded from an electronic hospital database system and compared among all groups.

Results: Of the 10,592 patients included in the study, 7,864 were admitted as outpatients, 2,233 to the wards, and 495 to ICU. Neutrophilic COPD patients $(n=6,536,62 \%)$ had increased inflammatory markers compared with eosinophilic COPD patients $(\mathrm{n}=4,056,38 \%)$; median NLR was 5.11 vs $2.62(P<0.001)$, PLR was 175.66 vs $130.00(P<0.001)$, and CRP was 11.6 vs $7.7(P<0.001)$. All values increased relative to admission to the outpatient clinic, ward, or ICU: median NLR was 3.20, 6.33, and 5.94, respectively, median PLR was 140.43, 208.46, and 207.39, respectively, and median CRP was 6.4, 15.0, and 22.8, respectively. The median NLR values of patients in outpatients/ward/ICU increased in neutrophilic and eosinophilic endotypes: $4.21 / 7.57 / 8.60(P<0.001)$ and 2.50/3.43/3.42 $(P=0.81)$, respectively. CRP showed a similar increased pattern according to severity of AECOPD endotypes.

Conclusion: In COPD exacerbation, the inflammatory markers show different increases in each COPD endotypes. These findings may be crucial for defining exacerbation endotypes, the severity of exacerbation, and treatment response during follow-up in COPD patients.

Keywords: outpatients, inflammatory biomarkers, COPD attack, ward and intensive care, hospitalization

\section{Introduction}

COPD exacerbation requiring hospitalization is one of the most important causes of morbidity and mortality. ${ }^{1}$ When acute respiratory failure occurs due to acute exacerbation of COPD (AECOPD), and intensive care unit (ICU) admission is needed, mortality risk is increased. ${ }^{2}$

The predominant reason for AECOPD is an infectious origin, and nearly half of these are bacterial infections. ${ }^{3,4}$ Airway inflammatory cells indicate the severity 
and etiology of AECOPD. When neutrophils predominate in the airways, the exacerbation tends to be severe, while airway eosinophilia at the time of exacerbation indicates a viral etiology. ${ }^{3,4}$ Recent studies showed a good correlation between sputum and peripheral blood eosinophil (PBE) count in patients with COPD. In addition, $\mathrm{PBE} \geq 2 \%$ was shown to be a valuable indicator of corticosteroid response..$^{5-8}$

There have been some useful recent treatment approaches using clinical and symptomatic findings. Respiratory symptoms, for example, dyspnea, cough, sputum, wheezing, and airway limitation (either increased resistance, ie, decreased $\mathrm{FEV}_{1}$ or decreased elastic recoil, ie, emphysema), may be useful in determining and treating AECOPD endotypes, namely neutrophilic and eosinophilic. ${ }^{9}$ These AECOPD endotypes may lead to varying levels of increased inflammatory markers.

Recent studies have shown promising results with infectious inflammatory markers such as C-reactive protein (CRP), neutrophil to lymphocyte ratio (NLR), platelet to lymphocyte ratio (PLR), platelet/mean platelet volume (PLT/MPV), and procalcitonin, and may represent useful tools for physicians managing AECOPD patients. ${ }^{10-14}$

The present study was conducted retrospectively in a 503-bedded, chest disease, teaching center hospital with previously diagnosed COPD patients admitted to the outpatients' clinic, ward, and ICU. We hypothesized that an early assessment of peripheral blood NLR and PBE percentage may be helpful for determining the severity of the AECOPD and the appropriate treatment approach.

\section{Methods}

\section{Study design}

A retrospective observational cross-sectional study was performed in the Health Science University Istanbul Sureyyapasa Chest Diseases and Thoracic Surgery Training and Research Hospital between January 2016 and December 2017. This study was approved by the local scientific committee of Hospital (date 08.11.2017/No:001). Ethical approval was in accordance with the Declaration of Helsinki. All data were collected retrospectively from the hospital database. Informed consent was not obtained from patients for the use of medical data for publication purposes since this was waived by the institution's local scientific committee, in line with the local legislation due to the retrospective nature of the study. All patients' ID information was strictly protected.

\section{Patients}

A COPD diagnosis was previously made by a pulmonary specialist in our center if the patient was $>40$ years, smoked $>10$ packs/year or had been exposed to cigarette smoke. Patients with concurrent disease/s, for example, lung cancer, pneumonia, rheumatologic diseases with pulmonary involvement, interstitial lung diseases, asthma and rhinitis, chronic liver and renal diseases, and chronic neurological muscular diseases that may have contributed to these respiratory symptoms, or those with missing complete blood count (CBC) values, were excluded from the study.

Patients were divided according to endotypes, and further subdivided according to where they were admitted within the hospital as an indicator of exacerbation severity, that is, to the outpatient clinic, ward, or ICU. Patient enrollment is summarized in a flowchart in Figure 1.

\section{Definitions \\ ICD codes}

J44.0-44.9: J44 Other COPD

J44.0 COPD with acute lower respiratory infection

J44.1 COPD with (acute) exacerbation

J44.9 COPD, unspecified.

\section{COPD}

Patients who had, an $\mathrm{FEV}_{1} / \mathrm{FVC}<70 \%$ predicted, and had a history or physical evidence of dyspnea, cough, sputum, and wheezing. ${ }^{1}$ Spirometry values were not recorded due to the absence of an electronic database.

\section{Neutrophilic COPD}

If the percentage of PBEs was $<2 \%$, it was accepted as neutrophilic COPD.

\section{Eosinophilic COPD}

If the percentage of PBEs was $\geq 2 \%$, it was accepted as eosinophilic COPD. ${ }^{5}$

\section{Acute exacerbation of COPD}

It is an acute change in a patient's respiratory symptoms such as dyspnea, sputum production, volume and color change, and requires a change in current therapy. ${ }^{1}$

\section{Neutrophil to lymphocyte ratio}

As a marker of systemic inflammation, NLR was defined as absolute neutrophil count divided by absolute lymphocyte count.

\section{Platelet to lymphocyte ratio}

PLR was defined as the absolute platelet count divided by absolute lymphocyte count. ${ }^{15}$ 
Previously diagnosed COPD patients admitted to the hospital in January 1, 2016-December 31, 2016 $\mathrm{N}=43,315$ (outpatients: 34,775 , ward: 6,696 , ICU: 1,844)

\begin{tabular}{|c|c|}
\hline $\begin{array}{l}\text { Included } \\
\text { Previous diagnosed COPD } \\
\text { (ICD coding J 44) } \\
\text { Age above } 40 \text { years } \\
\text { CBC values on the first day of hospitalization }\end{array}$ & $\begin{array}{l}\text { Excluded } \\
\text { Pneumonia, malignancy } \\
\text { Asthma, rhinitis } \\
\text { Liver or renal diseases } \\
\text { Rheumatological or neurological diseases } \\
\text { Any interstistial lung involvement } \\
\text { Missing CBC values }\end{array}$ \\
\hline
\end{tabular}

COPD patients stratified according to peripheral blood eosinophil percent, $\mathrm{N}=10,592$

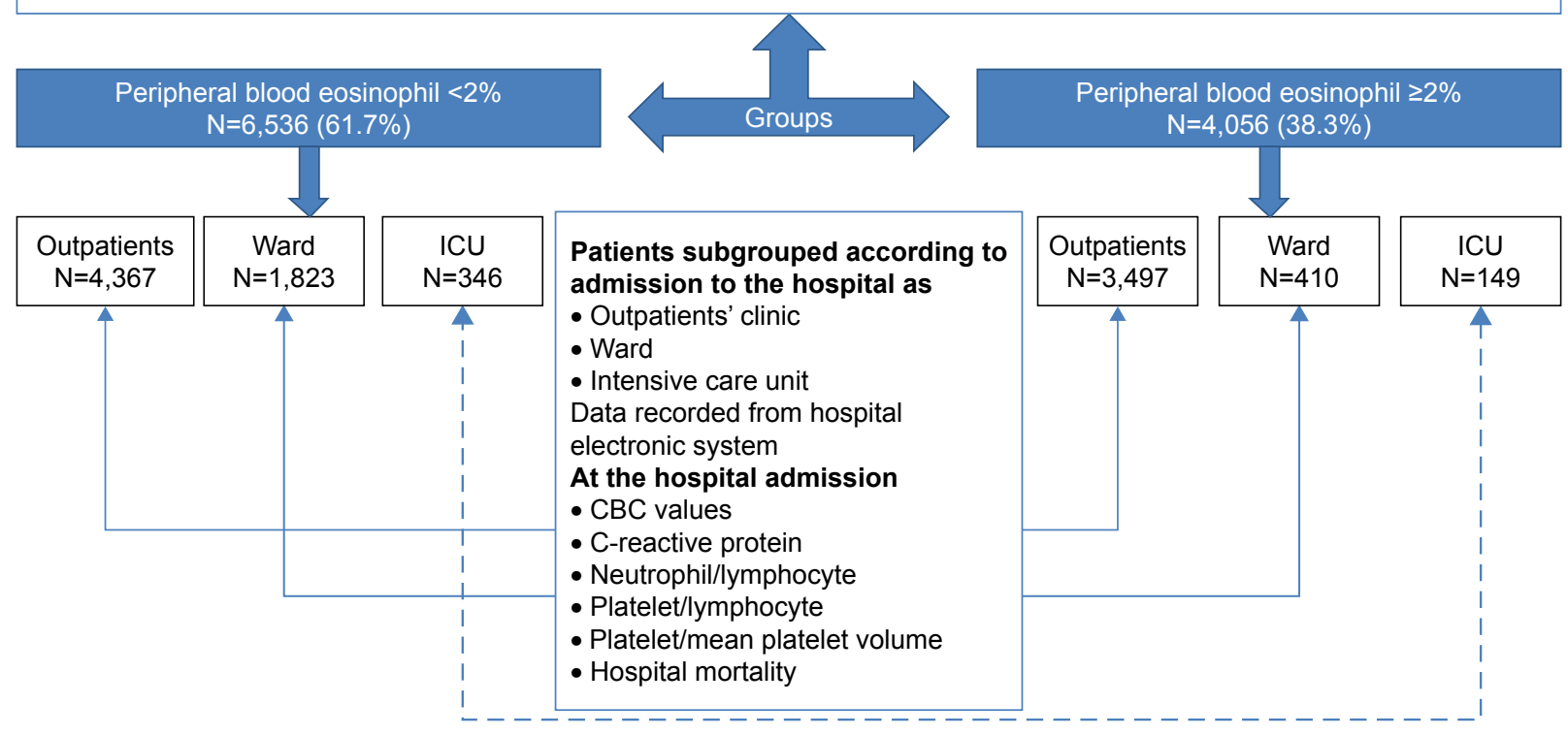

Figure I Flowchart of patient data.

Abbreviations: $\mathrm{CBC}$, complete blood count; ICU, intensive care unit.

\section{Platelets/MPV ratio}

As a marker of systemic inflammation, the ratio of platelet count to MPV was calculated.

\section{Comorbidities}

These were recorded from the patients' electronic data file and included diabetes mellitus, hypertension, congestive heart failure, coronary artery disease, arrhythmia, renal failure, anemia, and anxiety/depression.

\section{Study center protocol for ward and ICU admission,} and outpatient clinic follow-up

In the study center, COPD patient hospitalization and outpatient follow-up were designed using the international/national COPD guidelines. ${ }^{1,16}$

\section{Criteria for admission to the ward}

Indication for hospital admission to the ward was according to the GOLD guidelines, that is, a marked increase in intensity of symptoms, severe underlying COPD, onset of new physical signs, failure of an exacerbation to respond to initial medical management, presence of serious comorbidities, frequent exacerbations, older age, and insufficient home support. ${ }^{1}$

\section{Criteria for admission to the ICU}

The decision to admit the patient to the ICU was made according to the following GOLD guidelines: severe dyspnea that responds inadequately to initial emergency therapy, changes in mental status (confusion, lethargy, coma), persistent or worsening hypoxemia and/or severely worsening respiratory acidosis despite supplemental oxygen and noninvasive ventilation, the need for invasive mechanical ventilation, and/or hemodynamic instability. ${ }^{1}$

\section{Recorded data}

Patient information recorded from the hospital database included age, gender, CBC and blood biochemistry values, laboratory results on admission at the hospital, and 
comorbidities. As inflammatory markers, total leukocyte count, neutrophil count, NLR, PLT/MPV, and CRP were recorded. Pulmonary function tests could not be obtained because of the absence of an electronic database of spirometry values. Nonetheless, the study authors checked all patients' findings if they appeared suspicious.

CBC counts including total leukocyte, neutrophil, eosinophil, lymphocyte, platelet counts, and MPV were determined using a Coulter LH 780 Hematology Analyzer (Beckman Coulter, Atlanta, GA, USA). CRP was determined using the nephelometry method BN II System (Siemens, Munich, Germany). The normal range of CRP is $0-5 \mathrm{mg} / \mathrm{L}$.

\section{Statistical analysis}

Statistical analysis was done using the portable SPSS-20 version package program. Patient demographics and all clinical data were summarized by descriptive analysis. The Student's $t$-test was used for continuous variables (ie, age, CBC values, biochemistry values, NLR, PLR, PLT/MPV, and CRP), if distributed normally in the two groups. The values from the Student's $t$-test were shown as the mean $\pm \mathrm{SD}$. If the groups were distributed nonnormally, the nonparametric Mann-Whitney $U$ test was used, and the values were shown as the median and interquartile range. Dichotomous values (gender and presence of comorbid diseases) were compared using the chi-squared test. If $\mathrm{n}<5$, the Fisher's exact test was used and values were shown as count and percentage. The Kruskal-Wallis nonparametric test was used for comparison of inflammatory markers of COPD patients according to where they were admitted (outpatient clinic, ward, or ICU). To define the hospital mortality cutoff values of NLR, PLR, PLT/MPV, and CPR, the receiver operating characteristic (ROC) curve was used, and the area under the curve (AUC) was obtained to determine the optimal cutoff values. If the $P$-value was $<0.05$, it was accepted as statistically significant.

\section{Results}

In the study period, hospital electronic database revealed within the J 44.0-J 44.9 International coding system 43,315 patients were admitted to the hospital, either to the outpatient clinic, the ward, or the ICU. These "COPD" codes indicate an exacerbation or a comorbid disease. The study enrollment criteria resulted in 10,592 AECOPD patients being included in the study (Figure 1). The patients with AECOPD stratification, that is, according to endotype, are summarized in Figure 1. Both groups were subdivided according to where they were admitted to the hospital (Figure 1). The majority of
COPD patients were excluded from the study due to absence of CBC values on the day of hospitalization.

Table 1 shows the comparison of neutrophilic and eosinophilic endotype groups relative to demographics, comorbidities, CBC, and biochemistry values, inflammatory markers at the time of admission to the hospital, place of admission to the hospital (outpatient clinic, ward, or ICU), and ward and ICU mortality. The CBC and biochemistry values from both groups were statistically, but not clinically, significant. The eosinophilic endotype was seen in nearly $38.3 \%$ of the included patients. In-hospital mortality was observed in 32 of the 2,728 hospitalized patients with AECOPD (16 of which were in the ICU).

Table 2 shows the comparison of eosinophilic and neutrophilic AECOPD patients' inflammatory markers on admission to the outpatient clinic, the ward, or the ICU. Relative to disease severity, CRP, white blood cell count, NLR, and PLR were all significantly increased, and PLT/MPV was significantly decreased (Table 2).

Table 3 shows a comparison of inflammatory markers relative to disease severity based on where the patient was admitted, and in both AECOPD endotypes CRP was significantly increased relative to attack severity. Neutrophilic AECOPD patients had statistically significant increased NLR values as the attack severity increased while NLR did not increase with attack severity in eosinophilic AECOPD patients.

The cutoff values for NLR, PLR, PLT/MPV, and CRP in hospital mortality were analyzed by the ROC and AUC and are summarized in Figure 2 and Table 4, respectively. Among the inflammatory markers, the highest AUC for hospital mortality was obtained with NLR.

Table 4 shows inflammatory marker values relative to hospital mortality in patients with AECOPD compared by the area under the ROC curve analysis.

The cutoff values of NLR, CRP, PLR, and PLT/MPV for mortality are summarized in Table 5.

\section{Discussion}

The present study showed that the inflammatory markers NLR, CRP, and PLR (but not PLT/MPV ratio) in patients with eosinophilic and neutrophilic endotypes of AECOPD increased significantly relative to disease severity. The increase in NLR was far more significant in neutrophilic AECOPD, compared with eosinophilic AECOPD. Relative to disease severity, the PLT/MPV ratio decreased in AECOPD patients. NLR and CRP were better predictors of hospital mortality than the other inflammatory markers. 
Table I Baseline characteristics of neutrophilic and eosinophilic acute exacerbation of COPD

\begin{tabular}{|c|c|c|c|}
\hline & $\begin{array}{l}\text { Neutrophilic COPD } \\
N=6,537\end{array}$ & $\begin{array}{l}\text { Eosinophilic COPD } \\
\mathrm{N}=4,056\end{array}$ & $P$-value \\
\hline Age, median (IQR) years ${ }^{\mathrm{a}}$ & $69(61-77)$ & $67(59-75)$ & $<0.001$ \\
\hline Male, n (\%) & $4,325(66)$ & $2,931(72)$ & $<0.001$ \\
\hline \multicolumn{4}{|l|}{ CBC, median (IQR) values ${ }^{a}$} \\
\hline Leucocyte count, $10^{9} \mathrm{~L}$ & $9.90(7.80-12.80)$ & $8.30(6.90-9.99)$ & $<0.001$ \\
\hline Neutrophil count & $7.90(5.40-10.20)$ & $5.10(4.00-6.59)$ & $<0.001$ \\
\hline Lymphocyte count & $1.50(0.95-2.10)$ & $1.91(1.50-2.50)$ & $<0.001$ \\
\hline Monocyte count & $0.60(0.48-0.90)$ & $0.62(0.50-0.80)$ & 0.036 \\
\hline Erythrocyte count, $10^{12} \mathrm{~L}$ & $4.64(4.18-5.07)$ & $4.76(4.36-5.15)$ & $<0.001$ \\
\hline Hemoglobin, g/dL & $\mid 3.0(|| .0-\mid 4.0)$ & $14.0(\mid 2.0-15.0)$ & $<0.001$ \\
\hline Hematocrit, \% & $40(36-44)$ & $41(36-44)$ & 0.25 \\
\hline $\mathrm{MCV}, \mathrm{fL}$ & $86.6(82.5-90.4)$ & $86.8(82.9-90.3)$ & 0.25 \\
\hline Platelet count, $10^{9} \mathrm{~L}$ & $256(206-320)$ & $252(209-307)$ & 0.08 \\
\hline Mean platelet volume & $8(8-9)$ & $8(8-9)$ & 0.64 \\
\hline \multicolumn{4}{|c|}{ Biochemistry, median (IQR) values ${ }^{\mathrm{a}}$} \\
\hline Blood glucose, mg/dL & $132(106-176)$ & $112(95-142)$ & $<0.001$ \\
\hline BUN, mg/dL & $44(33-62)$ & $38(30-5 I)$ & $<0.001$ \\
\hline Serum creatinine, $\mathrm{mg} / \mathrm{dL}$ & $0.78(0.6 \mathrm{I}-\mathrm{I} .0 \mathrm{I})$ & $0.80(0.62-1.01)$ & 0.92 \\
\hline AST, U/L & $22(17-33)$ & $22(17-29)$ & 0.005 \\
\hline $\mathrm{ALT}, \mathrm{U} / \mathrm{L}$ & $18(12-29)$ & $16(12-24)$ & $<0.001$ \\
\hline Albumin, g/dL & $3.6(3.2-3.9)$ & $3.7(3.3-4.0)$ & $<0.001$ \\
\hline Sodium, $\mathrm{mmol} / \mathrm{L}$ & $138(135-140)$ & $138(136-140)$ & $<0.001$ \\
\hline Potassium, $\mathrm{mmol} / \mathrm{L}$ & $4.4(4.0-4.8)$ & $4.4(4.1-4.7)$ & 0.049 \\
\hline \multicolumn{4}{|c|}{ Inflammatory markers, median (IQR) values ${ }^{a}$} \\
\hline Neutrophil to lymphocyte ratio & $5.11(2.92-9.64)$ & $2.62(1.88-3.80)$ & $<0.001$ \\
\hline Platelet to lymphocyte ratio & I75.66 (I I8.46-28I.II) & $130.00(98.66-175.38)$ & $<0.001$ \\
\hline Platelet to MPV ratio & $31(24-40)$ & 30 (24-39) & 0.18 \\
\hline CRP, mg/dL & II.6 (4.0-36.4) & $7.7(3.4-21.2)$ & $<0.001$ \\
\hline \multicolumn{4}{|c|}{ Admission to the hospital, $n(\%)$} \\
\hline Outpatient clinic & $4,367(67)$ & $3,497(86)$ & $<0.001$ \\
\hline Ward & $\mathrm{I}, 823(28)$ & $410(10)$ & \\
\hline ICU & $346(5)$ & $149(4)$ & \\
\hline Mortality, n (\%) & $29(0.4)$ & $3(0.1)$ & 0.001 \\
\hline
\end{tabular}

Note: a Median (25\%-75\%), Mann-Whitney $U$ test.

Abbreviations: ALT, alanine aminotransferase; AST, aspartate aminotransferase; BUN, blood urea nitrogen; CBC, complete blood count; CRP, C-reactive protein; $I C U$, intensive care unit; IQR, interquartile range; MCV, mean corpuscular volume; MPV, mean platelet volume.

\section{Pathobiological mechanisms (endotypes) of exacerbation of COPD: eosinophilic and neutrophilic}

Since the last decade there have been many studies on the COPD endotypes with the aim of developing targeted and more effective therapeutic alternatives, or altering existing strategies. Recently, Agustí et al reviewed the implications of endotyping with respect to treatment in patients with COPD. ${ }^{9}$ Clinical presentations of COPD or "phenotypes" result from the endotypes that indicate the pathobiological mechanisms, which are effected by exposome, that is, cumulative exposure of cigarette smoking, air pollution, infections, foods and allergens, and related to genome. ${ }^{9,17}$ In the present study, we investigated the biomarkers NLR, PLR, PLT/MPV, and CRP in patients with a clinical presentation of AECOPD with varying severity and different underlying endotypes. Our results, as well as current knowledge, point to the use of different biomarkers in the different endotypes to assess treatment response in the follow-up period.

In the present study, the presence of the eosinophilic endotype was found to be higher in the mild-to-moderate AECOPD group. Previous studies have also found that the PBE count is decreased relative to the exacerbation severity. ${ }^{18-22}$ One may assume that patients with the eosinophilic endotype may have a good response to a treatment approach such as steroids. However, Vedel-Krogh et al recently published a study on patients with COPD exacerbations and revealed that those 
Table 2 Comparison of inflammatory markers in neutrophilic and eosinophilic COPD exacerbation

\begin{tabular}{|c|c|c|c|c|c|}
\hline & \multicolumn{2}{|c|}{$\begin{array}{l}\text { Neutrophilic (PBE }<2 \% \text { ) } \\
N=6,537\end{array}$} & \multicolumn{2}{|c|}{$\begin{array}{l}\text { Eosinophilic (PBE } \geq 2 \% \text { ) } \\
\mathrm{N}=\mathbf{4 , 0 5 6}\end{array}$} & \multirow[t]{2}{*}{$P$-value } \\
\hline & $\mathbf{N}$ & Variables & $\mathbf{N}$ & Variables & \\
\hline \multicolumn{6}{|c|}{ Outpatient clinic } \\
\hline Patients $^{\mathrm{a}}$ & 4,367 & - & 3,497 & - & \\
\hline WBC $\left(10^{9} \mathrm{~L}\right)$ & 4,367 & $9.70(7.76-12.50)$ & 3,497 & $8.30(6.90-9.93)$ & $<0.001$ \\
\hline NLR & 4,367 & $4.21(2.58-7.47)$ & 3,497 & $2.50(1.83-3.62)$ & $<0.001$ \\
\hline CRP (mg/dL) & 1,276 & $7.7(3.4-22.7)$ & $\mathrm{I}, 445$ & $5.7(3.3-12.7)$ & $<0.001$ \\
\hline $\mathrm{PLT} / \mathrm{MPV} \times 10^{3}$ & 4,367 & $32(24-4 I)$ & 3,497 & $31(24-39)$ & 0.004 \\
\hline PLR & 4,367 & I55.53 (| I0.50-236.67) & 3,497 & I 26.54 (97.53-169.09) & $<0.001$ \\
\hline \multicolumn{6}{|l|}{ Ward } \\
\hline Patients $^{\mathrm{a}}$ & I,823 & - & 410 & - & \\
\hline WBC $\left(10^{9} \mathrm{~L}\right)$ & 1,823 & $10.20(8.00-13.10)$ & 410 & $8.20(6.60-10.20)$ & $<0.001$ \\
\hline NLR & $\mathrm{I}, 823$ & $7.57(4.29-13.20)$ & 410 & $3.43(2.44-4.92)$ & $<0.001$ \\
\hline CRP $(\mathrm{mg} / \mathrm{dL})$ & I,788 & $14.0(4.6-42.3)$ & 402 & $19.0(8.4-4 \mid .7)$ & $<\mathbf{0 . 0 0 1}$ \\
\hline PLT/MPV & $\mathrm{I}, 823$ & $30(23-40)$ & 410 & $29(22-40)$ & 0.49 \\
\hline PLR & I,823 & $228.33(145.38-366.67)$ & 410 & $156.37(|| 4.2|-2| 6.67)$ & $<0.001$ \\
\hline \multicolumn{6}{|l|}{ ICU } \\
\hline Patients $^{\mathrm{a}}$ & 346 & - & 149 & - & \\
\hline WBC $\left(10^{9} \mathrm{~L}\right)$ & 346 & $10.07(7.70-13.40)$ & 149 & $8.30(7.00-9.81)$ & $<0.001$ \\
\hline NLR & 346 & $8.60(4.53-16.60)$ & 149 & $3.42(2.57-5.10)$ & $<0.001$ \\
\hline CRP $(\mathrm{mg} / \mathrm{dL})$ & 337 & $20.4(8.6-67.6)$ & 147 & $25.1(12.9-47.6)$ & 0.90 \\
\hline PLT/MPV & 346 & $28(2 \mid-38)$ & 149 & $27(20-35)$ & 0.19 \\
\hline PLR & 346 & $246.88(159.74-433.33)$ & 149 & |43.85 (| | 2.78-204.|7) & $<0.001$ \\
\hline
\end{tabular}

Note: aedian and interquartile range (25th-75th percentile). Significant values are written bold.

Abbreviations: CRP, C-reactive protein; ICU, intensive care unit; NLR, neutrophil to lymphocyte ratio; PBE, peripheral blood eosinophilia; PLR, platelet to lymphocyte ratio; PLT/MPV, platelet to mean platelet volume; WBC, white blood cell count.

COPD patients with blood eosinophils $>0.34 \times 10^{9}$ cells $/ \mathrm{L}$ were found to be at increased risk of either moderate or severe AECOPD. ${ }^{23}$ They showed the eosinophilic endotype to be associated with increased exacerbation. Some recent studies have shown a good response to steroid treatment in AECOPD patients with a predominance of PBEs. ${ }^{5,7,24,25}$ In previous studies neutrophilic AECOPD was defined as having an NLR $>3.54$, and this was an indicator for considering antibiotic treatment. ${ }^{18}$ We demonstrated that NLR values in neutrophilic group increased gradually relative to

Table 3 Comparison of inflammatory markers in AECOPD patients on the day of admission to the ICU, ward, or outpatients' clinic

\begin{tabular}{|c|c|c|c|c|c|c|c|}
\hline & \multicolumn{2}{|c|}{ ICU } & \multicolumn{2}{|l|}{ Ward } & \multicolumn{2}{|c|}{ Outpatients' clinic } & \multirow[t]{2}{*}{$P$-value ${ }^{a}$} \\
\hline & $n$ & Median (25\%-75\%) & $\mathbf{n}$ & Median (25\%-75\%) & n & Median (25\%-75\%) & \\
\hline \multicolumn{8}{|l|}{ Total patient } \\
\hline $\mathrm{CRP}(\mathrm{mg} / \mathrm{dL})$ & 484 & $22.8(9.9-55.3)$ & 2,190 & $15.0(5.2-42.2)$ & 2,721 & $6.4(3.4-16.8)$ & $<0.001$ \\
\hline NLR & 495 & $5.94(3.40-12.87)$ & 2,233 & $6.33(3.58-11.6)$ & 7,864 & $3.20(2.12-5.45)$ & $<0.001$ \\
\hline PLR & 495 & 207.39 (134.68-348.57) & 2,233 & 208.46 (I36.39-337.78) & 7,864 & I 40.43 (I03.64-202.35) & $<0.001$ \\
\hline PLT/MPV & 495 & $27.9(20.7-36.4)$ & 2,233 & $29.6(22.5-39.6)$ & 7,864 & $31 . I(24.3-40.1)$ & $<0.001$ \\
\hline \multicolumn{8}{|l|}{ Neutrophilic } \\
\hline CRP (mg/dL) & 337 & $20.4(8.6-67.6)$ & $\mathrm{I}, 788$ & $14.0(4.6-42.3)$ & 1,276 & 7.7 (3.4-22.7) & $<0.001$ \\
\hline NLR & 346 & $8.60(4.53-16.60)$ & $\mathrm{I}, 823$ & $7.57(4.29-13.20)$ & 4,367 & 4.21 (2.58-7.47) & $<0.001$ \\
\hline PLR & 346 & 246.88 (I59.74-433.33) & 1,823 & $228.33(145.38-366.67)$ & 4,367 & 155.53 (I I0.50-236.67) & $<0.001$ \\
\hline PLT/MPV & 346 & $28.2(21.1-37.7)$ & $\mathrm{I}, 823$ & $29.6(22.5-39.6)$ & 4,367 & $31.7(24.2-40.9)$ & $<0.001$ \\
\hline \multicolumn{8}{|l|}{ Eosinophilic } \\
\hline $\mathrm{CRP}(\mathrm{mg} / \mathrm{dL})$ & 147 & $25.1(\mid 2.9-47.6)$ & 402 & $19.0(8.4-4 \mid .7)$ & 1,445 & $5.7(3.3-12.7)$ & $<0.001$ \\
\hline NLR & 149 & $3.42(2.57-5.10)$ & 410 & $3.43(2.44-4.92)$ & 3,497 & $2.50(1.83-3.62)$ & 0.82 \\
\hline PLR & 149 & I 43.85 (| | 2.78-204.17) & 410 & $\mid 56.37$ (| |4.2|-2|6.67) & 3,497 & I26.54 (97.53-169.09) & $<0.001$ \\
\hline PLT/MPV & 149 & $26.9(19.6-35.0)$ & 410 & $29.5(22.2-39.9)$ & 3,497 & $30.5(24.3-39.0)$ & 0.09 \\
\hline
\end{tabular}

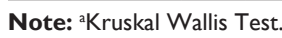

Abbreviations: AECOPD, acute exacerbation of Chronic Obstructive Pulmonary Disease; CRP, C-reactive protein; ICU, intensive care unit; NLR, neutrophil to lymphocyte ratio; PLR, platelet to lymphocyte ratio; PLT/MPV, platelet to mean platelet volume. 


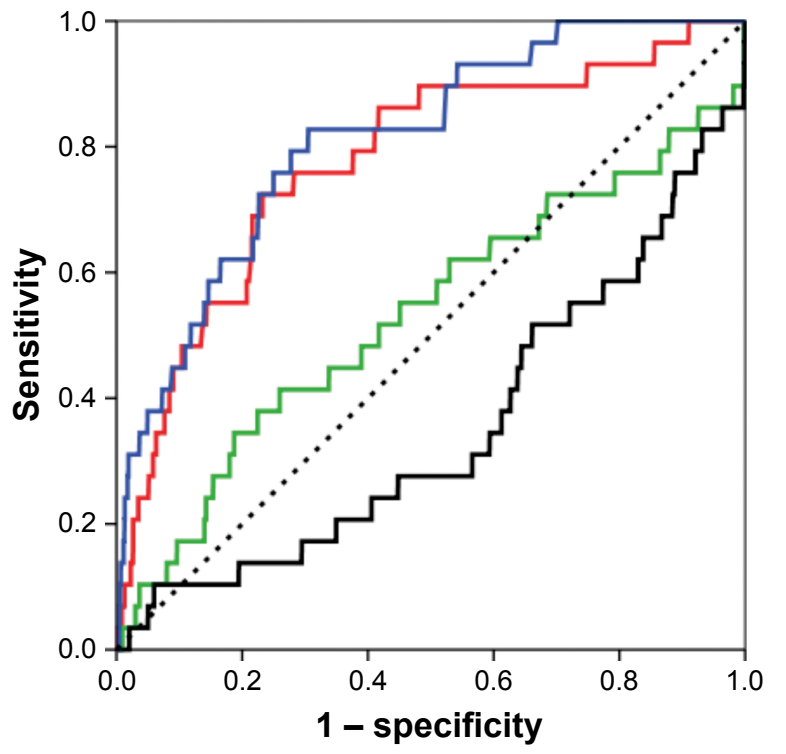

Source of the curve

- NLR - PLR - PLT/MPV - CRP ... Reference line

Figure 2 ROC curves of inflammatory markers for mortality of hospitalized COPD acute exacerbation patients.

Note: Diagonal segments are produced by ties.

Abbreviations: ROC, receiver operating characteristic; PLR, platelet to lymphocyte ratio; PLT/MPV, platelet/mean platelet volume; CRP, C-reactive protein; NLR, neutrophil to lymphocyte ratio.

where the patient was admitted, that is, outpatient, ward, and ICU. However, NLR values in the eosinophilic group were at similarly low levels regardless of where the patient was admitted (Figure 2).

CRP showed a similar increase with increased severity in both endotypes of AECOPD indicating a direct association of CRP and the severity of COPD exacerbation. While NLR values increased with severity in the neutrophilic group, we found no significant change in NLR with the severity of COPD exacerbation in the eosinophilic endotype, and in fact the NLR values in the eosinophilic endotype were within the normal range for NLR (normal NLR $=1.65$ range 0.78-3.53). ${ }^{26}$ Thus, in the case of AECOPD where the CRP

Table 4 Area under the curve of inflammatory markers in patients with AECOPD who died in the hospital

\begin{tabular}{|c|c|c|c|c|}
\hline \multirow[t]{2}{*}{ Test result variable(s) } & \multirow[t]{2}{*}{ Area } & \multicolumn{2}{|c|}{$\begin{array}{l}\text { Asymptotic } \\
95 \% \mathrm{Cl}\end{array}$} & \multirow[t]{2}{*}{$P$-values } \\
\hline & & $\begin{array}{l}\text { Lower } \\
\text { bound }\end{array}$ & $\begin{array}{l}\text { Upper } \\
\text { bound }\end{array}$ & \\
\hline C-reactive protein & 0.81 & 0.74 & 0.89 & $<0.001$ \\
\hline Neutrophil to lymphocyte ratio & 0.78 & 0.69 & 0.87 & $<0.001$ \\
\hline Platelet to lymphocyte ratio & 0.53 & 0.41 & 0.66 & 0.54 \\
\hline Platelet to mean platelet volume & 0.35 & 0.24 & 0.46 & 0.006 \\
\hline
\end{tabular}

Abbreviation: AECOPD, acute exacerbation of chronic obstructive pulmonary diseases.
Table 5 The cutoff values of inflammatory markers in patients with AECOPD who died in the hospital

\begin{tabular}{llll}
\hline Variables & Cutoff & $\begin{array}{l}\text { Sensitivity, } \\
\%\end{array}$ & $\begin{array}{l}\text { Specificity, } \\
\%\end{array}$ \\
\hline C-reactive protein & 35.1 & 81 & 60 \\
Neutrophil to lymphocyte ratio & 8.01 & 78 & 60 \\
Platelet to lymphocyte ratio & 228.87 & 52 & 55 \\
Platelet to mean platelet volume & 19.3 & 66 & 16 \\
\hline
\end{tabular}

Abbreviation: AECOPD, acute exacerbation of chronic obstructive pulmonary diseases.

levels increase with an increased severity of exacerbation, and the NLR is nearly normal or slightly elevated, it may be helpful to assess viral etiology before initiating antibiotic or steroid treatment. These results suggest using both CRP and NLR levels to predict severity and to determine the management of AECOPD.

Bafadhel et al defined four endotypes of AECOPD (with biomarkers) as follows: bacterial (sputum interleukin beta 1), viral (serum CXCL10), eosinophilic (blood eosinophil), and pauciinflammatory. ${ }^{5,27}$ Brightling proposed that we need a deeper understanding of the COPD phenotypes right from their genetic origin (ie, endotypes) through to the resultant phenotypes. ${ }^{10}$ Agustí et al recommended the treatment of COPD in four groups to be focused only on the pulmonary component and based on endotypes, that is, airway remodeling, neutrophilic, eosinophilic, and decrease apoptosis-increase repair presence of biomarkers and precision treatments respectively. ${ }^{9}$ The present study highlights the need for future molecular studies to investigate effector genes and treatment modalities of AECOPD (Figure 3).

A single study from the last two decades reported that CRP levels $>8 \mathrm{mg} / \mathrm{mL}$, together with Anthonisen et al's criteria, ${ }^{28}$ support the objective diagnosis of AECOPD. ${ }^{29}$ In the present study, CRP values in the outpatient clinic, ward, and ICU for patients with AECOPD increased relevant to severity. Günay et al showed that NLR values increased significantly in AECOPD (NLR =4.28) compared with stable COPD patients (NLR $=2.59$ ), and NLR values in COPD patients were significantly higher than healthy controls $(\mathrm{NLR}=1.71) .{ }^{11}$ Lee et al also studied NLR in patients with COPD. They found significantly higher levels of NLR in stable COPD patients compared with healthy controls, and if the level of NLR was $>2.8$, the risk of hospitalization increased. ${ }^{30}$ As the clinical deterioration proceeded in our study, the inflammatory markers, CRP, NLR, and PLR, were increased and PLT/MPV was decreased in both the eosinophilic and the neutrophilic endotypes. Yao et al found that higher levels of NLR $(>6.24)$, CRP $(>16.45 \mathrm{~g} / \mathrm{dL})$, and PLR $(>182.68)$ 


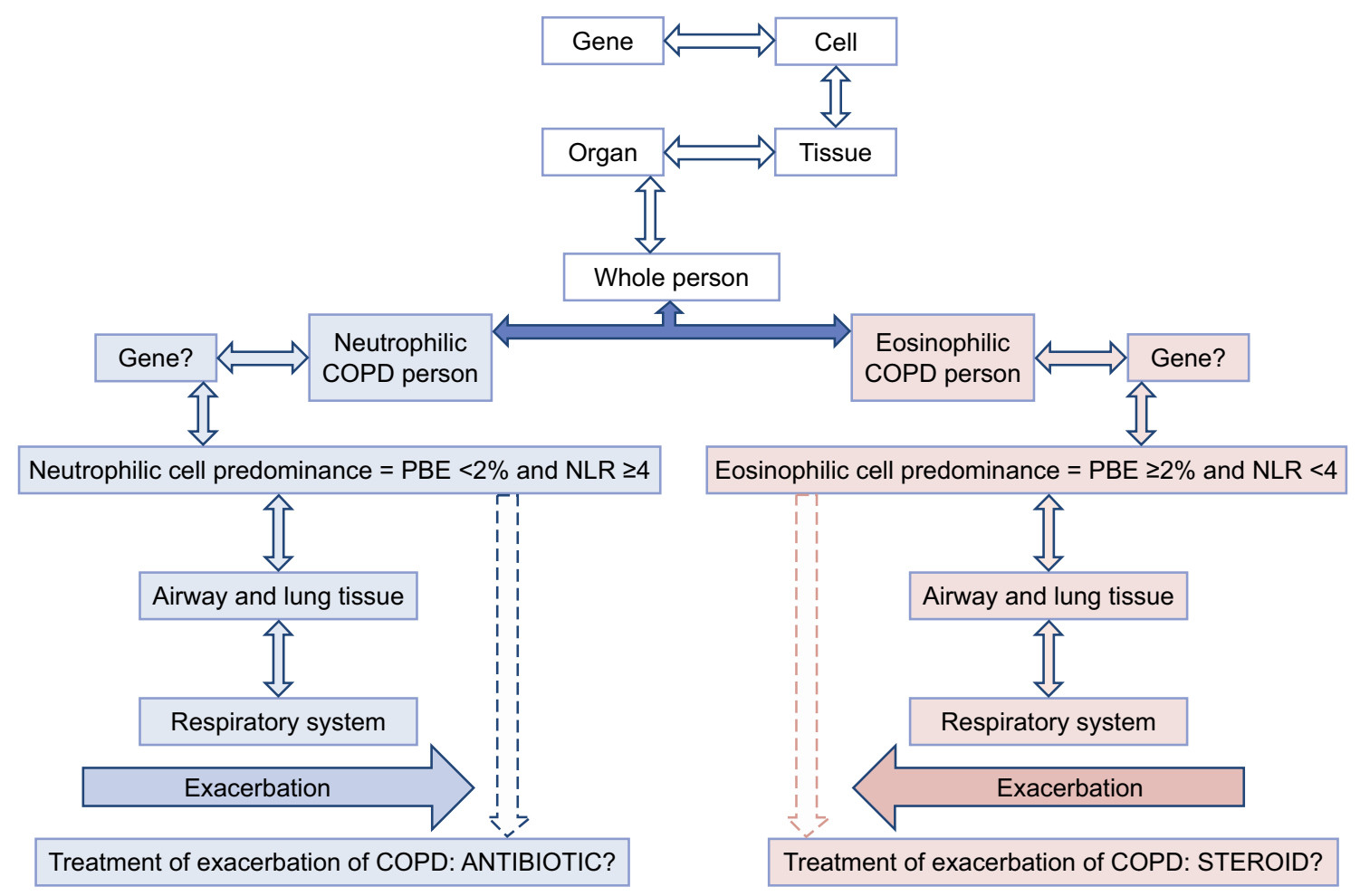

Figure 3 A treatment approach for chronic obstructive pulmonary diseases with respect to endotypes.

Abbreviations: PBE, peripheral blood eosinophil; NLR, neutrophil to lymphocyte ratio.

increased the risk of hospital mortality in AECOPD.${ }^{15}$ In the present study, NLR, CRP, and PLT/MPV showed significant values of ROC AUC for hospital mortality in hospitalized patients with AECOPD; however, PLR did not (Figure 2). The cutoff values of mortality of patients with AECOPD in the ward and ICU were higher than Yao's results.

\section{Limitations}

There are some limitations to this study. Firstly, it was of retrospective nature. All included patients were obtained using an electronic system after entering data selection rules which included having $\mathrm{CBC}$ values on the day of admission to the hospital and a diagnosis of AECOPD. Many potential study subjects were missed because their $\mathrm{CBC}$ values were on the day before or after admission to the hospital. Nonetheless, as the study values were obtained electronically using the hospital database, incorrect data entry was prevented. Secondly, the study was undertaken on a single disease (COPD) and our results cannot be generalized to all diseases. However, these study results involve a large number of COPD patients, are valuable, and worth considering for this specific disease. Thirdly, although the diagnosis of COPD was based on spirometry values, we were unable to show these values due to the fact that they were not electronically available in the system. Nonetheless, the study was conducted in a tertiary teaching hospital for chest diseases which is the biggest hospital in our country ( 503 beds for chest diseases only) and the diagnosis was made by a pulmonary specialist (under control and with other academic pulmonary specialists), with very little suspicion of misdiagnosis of COPD.

\section{Conclusion}

Despite technological advances and new biomarkers, there is still a current practice of looking only at leukocytes in CBC values as markers of infection. This study shows that NLR and PLR, calculated from CBC parameters, can be used to predict the severity of exacerbation of COPD. Similarly, NLR values in combination with physical findings may be useful when deciding where to admit the patient. If COPD patients with exacerbation have an NLR of 3.5-4.0, then the patient may be deemed suitable for outpatient follow-up without hospitalization. If the NLR is 6.5-7.0, we recommend hospitalization to the ward, and if the NLR is 13.0-14, admission to the ICU should be considered. We also recommend calculating the NLR and PLR values automatically and have these included in the $\mathrm{CBC}$ output, thus facilitating easier decision-making for the physicians in the outpatient clinics and emergency departments.

The present study findings may provide crucial information for defined exacerbation endotypes, the severity of exacerbation, and treatment response during follow-up with cheap, easy, and quick to obtain inflammatory markers. PBEs 
percentage, NLR and PLR may be used as biomarkers of AECOPD and may become important in medical decisions following future studies. These results may thus play a key role in clinical practice to prevent hospitalization and decrease the length of hospital stay and mortality in patients with AECOPD.

\section{Author contributions}

All authors contributed in the study, questions related to the work investigated by authors, and do not have any industry relationships for the past 2 years, and do not have any conflicts of interest. All authors contributed toward data analysis, drafting and revising the paper and agree to be accountable for all aspects of the work. EA contributed to conception and design, acquisition, analysis, interpretation of data, drafting the submitted article, and provided final approval to the version to be published. ZK contributed to analysis, interpretation of data, critical revision of the submitted article for important intellectual content, and provided final approval to the version. SG contributed to conception, interpretation of data, critical revision of the submitted article for important intellectual content, and provided final approval to the version. $\mathrm{BO}$ contributed to analysis, interpretation of data, and provided final approval to the version. IO and EY contributed to conception, interpretation of data, and provided final approval to the version. ET contributed to conception, design, critical revision of the submitted article for important intellectual content, and provided final approval to the version. MCA contributed to conception, design, analysis, critical review of the submitted article for important intellectual content, and provided final approval to the version. NCG and NA contributed to conception, design, interpretation of data, critical revision of the submitted article for important intellectual content, and provided final approval to the version.

\section{Disclosure}

All the authors who have contributed to the study design do not have any industry relationships for the past 2 years. The manuscript has been read and approved by all the authors, and each author believes that the manuscript represents honest work. The authors report no conflicts of interest in this work.

\section{References}

1. Global Initiative for Chronic Obstructive Lung Disease [home page on Internet]. Global Strategy for Diagnosis, Management, and Prevention of COPD (updated 2012). Available from: http://www.goldcopd.org. Accessed August 25, 2016.

2. Khilnani GC, Banga A, Sharma SK. Predictors of mortality of patients with acute respiratory failure secondary to chronic obstructive pulmonary disease admitted to an intensive care unit: a one year study. BMC Pulm Med. 2004;4:12.
3. Sethi S, Murphy TF. Infection in the pathogenesis and course of chronic obstructive pulmonary disease. N Engl J Med. 2008;359(22): 2355-2365.

4. Papi A, Bellettato CM, Braccioni F, et al. Infections and airway inflammation in chronic obstructive pulmonary disease severe exacerbations. Am J Respir Crit Care Med. 2006;173(10):1114-1121.

5. Bafadhel M, McKenna S, Terry S, et al. Blood eosinophils to direct corticosteroid treatment of exacerbations of chronic obstructive pulmonary disease: a randomized placebo-controlled trial. Am J Respir Crit Care Med. 2012;186(1):48-55.

6. Bafadhel M, Davies L, Calverley PM, et al. Blood eosinophil guided prednisolone therapy for exacerbations of COPD: a further analysis. Eur Respir J. 2014;44(3):789-791.

7. Pascoe S, Locantore N, Dransfield MT, Barnes NC, Pavord ID Blood eosinophil counts, exacerbations, and response to the addition of inhaled fluticasone furoate to vilanterol in patients with chronic obstructive pulmonary disease: a secondary analysis of data from two parallel randomised controlled trials. Lancet Respir Med. 2015;3(6): 435-442.

8. Brightling CE, McKenna S, Hargadon B, et al. Sputum eosinophilia and the short term response to inhaled mometasone in chronic obstructive pulmonary disease. Thorax. 2005;60(3):193-198.

9. Agustí A, Celli B, Faner R. What does endotyping mean for treatment in chronic obstructive pulmonary disease? Lancet. 2017;390(10098): 980-987.

10. Brightling CE. Biomarkers that predict and guide therapy for exacerbations of chronic obstructive pulmonary disease. Ann Am Thorac Soc. 2013; 10(Suppl):214-219.

11. Günay E, Sarınç Ulaşlı S, et al. Neutrophil-to-lymphocyte ratio in chronic obstructive pulmonary disease: a retrospective study. Inflammation. 2014;37(2):374-380.

12. Lacoma A, Prat C, Andreo F, et al. Value of procalcitonin, C-reactive protein, and neopterin in exacerbations of chronic obstructive pulmonary disease. Int J Chron Obstruct Pulmon Dis. 2011;6:157-169.

13. Tanrıverdi H, Örnek T, Erboy F, et al. Comparison of diagnostic values of procalcitonin, C-reactive protein and blood neutrophil/lymphocyte ratio levels in predicting bacterial infection in hospitalized patients with acute exacerbations of COPD. Wien Klin Wochenschr. 2015; 127(19-20):756-763.

14. Wang RT, Li JY, Cao ZG, Li Y. Mean platelet volume is decreased during an acute exacerbation of chronic obstructive pulmonary disease. Respirology. 2013;18(8):1244-1248.

15. Yao C, Liu X, Tang Z. Prognostic role of neutrophil-lymphocyte ratio and platelet-lymphocyte ratio for hospital mortality in patients with AECOPD. Int J Chron Obstruct Pulmon Dis. 2017;12(12):2285-2290.

16. Köktürk N, Gürgün A, Şen E, et al. The View of Turkish Thoracic Society on the Report of the GOLD 2017 Global Strategy for the Diagnosis, Management and Prevention of COPD. Turk Thorac J. 2017;18(2):57-64.

17. Vrijheid M. The exposome: a new paradigm to study the impact of environment on health. Thorax. 2014;69(9):876-878.

18. Acartürk Tunçay E, Karakurt Z, Aksoy E, et al. Eosinophilic and noneosinophilic COPD patients with chronic respiratory failure: neutrophilto-lymphocyte ratio as an exacerbation marker. Int J Chron Obstruct Pulmon Dis. 2017;12(12):3361-3370.

19. Saltürk C, Karakurt Z, Adiguzel N, et al. Does eosinophilic COPD exacerbation have a better patient outcome than non-eosinophilic in the intensive care unit? Int J Chron Obstruct Pulmon Dis. 2015;10(10):1837-1846.

20. Duman D, Aksoy E, Agca MC, et al. The utility of inflammatory markers to predict readmissions and mortality in COPD cases with or without eosinophilia. Int J Chron Obstruct Pulmon Dis. 2015;11(10): 2469-2478.

21. Karakurt Z, Aksoy E, Duman D, et al. Eosinophilic COPD exacerbation: is there any difference in readmission, length of stay and mortality in the hospital. Am J Respir Crit Care Med. 2016;193:A5193.

22. Agca MC, Aksoy E, Duman D, et al. Does eosinophilia and neutrophilto-lymphocyte ratio effect hospital re-admission in cases of COPD exacerbation? Am J Respir Crit Care Med. 2016;193:A6240. 
23. Vedel-Krogh S, Nielsen SF, Lange P, Vestbo J, Nordestgaard BG. Blood eosinophils and exacerbations in chronic obstructive pulmonary disease. The Copenhagen General Population Study. Am J Respir Crit Care Med. 2016;193(9):965-974.

24. Siddiqui SH, Guasconi A, Vestbo J, et al. Blood eosinophils: a biomarker of response to extrafine beclomethasone/formoterol in chronic obstructive pulmonary disease. Am J Respir Crit Care Med. 2015; 192(4):523-525.

25. Pavord ID, Lettis S, Locantore N, et al. Blood eosinophils and inhaled corticosteroid/long-acting $\beta$-2 agonist efficacy in COPD. Thorax. 2016;71(2):118-125.

26. Forget P, Khalifa C, Defour JP, Latinne D, van Pel MC, de Kock M. What is the normal value of the neutrophil-to-lymphocyte ratio? $B M C$ Res Notes. 2017;10(1):12.
27. Bafadhel M, McKenna S, Terry S, et al. Acute exacerbations of COPD: identification of biological clusters and their biomarkers. Am J Respir Crit Care Med. 2011;184:662-671.

28. Anthonisen NR, Manfreda J, Warren CP, Hershfield ES, Harding GK, Nelson NA. Antibiotic therapy in exacerbations of chronic obstructive pulmonary disease. Ann Intern Med. 1987;106(2):196-204.

29. Hurst JR, Donaldson GC, Perera WR, et al. Use of plasma biomarkers at exacerbation of chronic obstructive pulmonary disease. Am J Respir Crit Care Med. 2006;174(8):867-874.

30. Lee SJ, Lee HR, Lee TW, et al. Usefulness of neutrophil to lymphocyte ratio in patients with chronic obstructive pulmonary disease: a prospective observational study. Korean J Intern Med. 2016;31(5):891-898.

\section{Publish your work in this journal}

The International Journal of COPD is an international, peer-reviewed journal of therapeutics and pharmacology focusing on concise rapid reporting of clinical studies and reviews in COPD. Special focus is given to the pathophysiological processes underlying the disease, intervention programs, patient focused education, and self management protocols.

\section{Dovepress}

This journal is indexed on PubMed Central, MedLine and CAS. The manuscript management system is completely online and includes a very quick and fair peer-review system, which is all easy to use. Visit http://www.dovepress.com/testimonials.php to read real quotes from published authors. 